\title{
O NÃO DITO: HISTÓRIA DA ESCOLA PRIMÁRIA RURAL NAS PÁGINAS DA REVISTA ESCOLA PORTUGUESA (PORTUGAL, 1934 - 1939) ${ }^{1}$
}

Sandra Cristina Fagundes de Lima*

\begin{abstract}
RESUMO
O tema dessa pesquisa é a escola primária rural em Portugal. No âmbito dessa temática selecionamos para investigação os editoriais da revista Escola Portuguesa (EP) em seus cinco primeiros anos de publicação, 1934 a 1939. A questão que propusemos para a análise consistiu em compreender se a EP, durante o período em questão, destinou algum espaço em seus duzentos e cinquenta e sete editoriais (total de números publicados no primeiro quinquênio) para debater os problemas que perpassavam a escola primária rural no país.
\end{abstract}

Palavras-chave: Revista Escola Portuguesa. Postos escolares. História do ensino rural em Portugal.

\begin{abstract}
This research approaches the rural primary school in Portugal. To explore the theme we have selected the editorials of magazine Portuguese School (PS) in its first five years of publication, from 1934 to 1939. The question we have proposed for the analysis consisted in understanding if during the period in question the PS allocated any space in its two hundred fiftyseven editorials (total figures published in the first quinquennium) to discuss the problems of the rural primary school in the country.
\end{abstract}

Keywords: Magazine Portuguese School. School posts. History of rural education in Portugal.

\footnotetext{
* Doutora em História pela Universidade de Campinas (UNICAMP). Professora associada da Faculdade de Educação e do Programa de Pós-Graduação em Educação (PPGED) da Universidade Federal de Uberlândia (UFU), Uberlândia-MG/Brasil. E-mail: sandralimaufu@gmail.com

1 Pesquisa de estágio pós-doutoral financiada pelo CNPq (Processo n. 201441/2011-0) e realizada no Instituto de Educação da Universidade de Lisboa, Portugal, sob a supervisão do Professor Catedrático Dr. Justino Magalhães, no período de janeiro a dezembro de 2012.
} 


\section{Introdução}

O interesse pela história da escola rural em Portugal decorre, em parte, do contato com os textos de Canário (2000), Adão (2007), Amiguinho (2003), Martins (2007) e Aleixo; Alves (2007). Após a leitura dos trabalhos publicados por esses autores, todos relativos à história da escola rural em Portugal, constatamos que essa instituição também desempenhou naquele país, sobretudo, até o final dos anos de 1950, um importante papel no que concerne à alfabetização das crianças, sem, no entanto, tal qual o ocorrido no Brasil (LIMA, 2009), ter gozado de prestígio. Conforme assinala Adão, referindo-se à escola rural durante o Estado Novo em Portugal e ao avanço do conhecimento historiográfico sobre essa realidade:

O ensino nas regiões rurais cada vez se destaca mais pelo abandono a que é votado, o qual está igualmente justificado quando olhamos para os edifícios escolares. [...] estima-se em $50 \%$ as escolas que não possuem instalações convenientes e grande número das restantes funciona com más condições de arejamento e higiene (ADÃO, 2007, p. 281).

Em 2000, Canário apontava que a escola rural existia como objeto de fato; no entanto, ainda não se havia transformado efetivamente em "objeto de estudo" em Portugal: "A escola no mundo rural é um tema periférico da actividade de investigação" (2000, p. 121). Com efeito, em levantamento preliminar feito em Lisboa em 2012 na base de dados da Biblioteca Nacional (http://www.bnportugal.pt/) e na Biblioteca do Instituto de Educação da Universidade de Lisboa (http://sibul.reitoria. ul.pt/), localizamos no período de 1990 a 2009 um total de apenas quinze dissertações de mestrado, uma tese de doutorado e uma monografia em que a palavra rural figura no título, seja para se referir às escolas, seja para tratar da sociedade rural. Com isso, constatamos que ainda se encontram em fase de consolidação as pesquisas que envolvem essa temática.

Deve-se enfatizar que, embora essa escola ainda ocupe um tímido lugar no rol das temáticas investigadas em Portugal, o mundo rural e a escola nele instalada existiram, e existem, como objeto social e assumem ainda importantes significados para a transformação de alguns aspectos 
relativos à realidade educacional portuguesa, daí a relevância em se conhecer a sua história. Conforme ressalta Canário (2000, p. 124-125),

A defesa da escola em contexto rural assenta, então, num triplo postulado: o primeiro consiste em considerar esta defesa como correspondendo à defesa do mundo rural no seu conjunto; o segundo consiste em considerar que a instituição escolar pode desempenhar um papel de produção social, contribuindo activamente para a revitalização social das zonas rurais [...]; o terceiro postulado consiste em considerar que, pelas suas características singulares, a pequena escola em contexto rural pode contribuir para 'reinventar' práticas pedagógicas e educativas, superadoras dos limites inerentes à forma escolar $[\ldots]$.

Partindo, então, dessa evidência, o tema desse artigo incide sobre a escola primária rural em Portugal. A partir dessa temática, selecionamos para investigação os editoriais da revista Escola Portuguesa (EP) em seus cinco primeiros anos de publicação, 1934 a 1939. A questão proposta para a análise consistiu em compreender se a EP durante o referido período quando "[...] a sociedade portuguesa era dominada pelo peso do mundo rural, composta por uma percentagem muito elevada de população agrícola, a maior parte da qual viva de seu trabalho assalariado" (ADÃO, 2007 , p. 269) - destinou algum espaço em seus duzentos e cinquenta e sete editoriais (total de números publicados no primeiro quinquênio) para debater os problemas que perpassavam a escola primária rural no país, ou para informar a existência dessa instituição.

\section{A escola rural em Portugal...}

Em 1930, 80 por cento dos sete milhões de portugueses viviam no campo. Portugal permanecia uma sociedade rural, com raras vilas e cidades de importância. As linhas férreas eram escassas, as estradas más ou inexistentes(MÔNICA, 1978, p. 69).

Em razão disso, 
Até a década de 1950, a agricultura mantinha grande relevo no conjunto da economia portuguesa; um em cada dois portugueses trabalhava na agricultura - 49\% em 1930, 51\% em 1940 e 48\% em 1950 (ADÃO, 2007, p. 269).

Mesmo havendo essa preeminência da população rural e do trabalho agrícola, as escolas rurais não estavam devidamente equipadas para atender as necessidades da população. De acordo com Martins (2007, p. 313),

$\mathrm{Na}$ verdade a maioria das instalações escolares nas zonas rurais das regiões da Beira Baixa e Beira Alta, nas primeiras décadas do século 20, estavam em 'casas' sem condições, mobiliadas com uns miseráveis trastes. Havia edifícios em construção com obras paralisadas (verbas esgotadas) ou escolas novas que nunca passaram de projetos [...].

No espaço rural as pessoas trabalhavam, constituíam as suas famílias, praticavam a religião, desenvolviam laços de solidariedade e entravam em contato com os rudimentos da leitura, do cálculo e da escrita. Esses conhecimentos chegavam de maneira informal aos campesinos em seu próprio ambiente doméstico e lhes serviam para a lida diária no trabalho agrícola. Em geral, eram saberes transmitidos por aqueles cujo domínio da leitura e da escrita se constituía em requisito suficiente para se tornarem professores particulares. Predominava nesse contexto a circulação de conteúdos adquiridos pelas famílias e transmitidos geracionalmente. Ao aproximar-se o início da terceira década do século XX, essa "rede doméstica de escolarização" começou gradativamente a ser substituída pela escola formal, o que não se fez sem a desconfiança das famílias, segundo relata Amiguinho (2003, p. 26) em suas memórias sobre a infância vivida no meio rural na região de Ouguela em Portugal:

Apenas a obrigatoriedade da escolaridade primária decretada, na década de 50, tinha quebrado ligeiramente a desvalorização da instrução entre as famílias de trabalhadores rurais. Convém, pois, recordar que não se tratava de uma exaltação obstinada e rude da ignorância, mas de uma expectativa (negativa) também forjada na imperativa sobrevivência econômica e social da família. 
As escolas existentes no meio rural português não gozaram de prestígio na época em que o campo abrigava a maior parte da população e nem se adequaram para atender às necessidades do aluno habitante e trabalhador do meio rural. O seu currículo, os seus horários, o calendário de avaliações e demais instrumentos que caracterizavam o seu funcionamento seguiam as mesmas diretrizes vigentes nos estabelecimentos de ensino instalados no meio urbano (ADÃO, 2007).

Em 1930, o índice de analfabetismo no país era muito elevado: a cada 100 portugueses 70 não sabiam ler (MÔNICA, 1978). Nesse contexto, era significativo o número de crianças habitantes do meio rural em idade escolar e não obstante registrava-se naquele espaço a carência de estabelecimentos de ensino. Essa discrepância teria implicado, ao longo das primeiras décadas do Estado Novo, a promoção de medidas oficiais visando minorar o problema da falta de escolas no meio rural e atenuar o elevado número de crianças iletradas.

No ano 1930, o governo português autorizou a criação de escolas fixas, denominadas incompletas, nas localidades rurais que abrigassem pelo menos trinta crianças em idade escolar. Em 1931, essas escolas teriam sido substituídas pelos postos de ensino (não se caracterizavam por escolas, uma vez que não se exigiam dos docentes uma formação específica, conforme discutiremos na sequência). Em 1936, esses postos de ensino são transformados em postos escolares ${ }^{2}$, com a justificativa de se constituírem como unidade embrionária de escola elementar, e, como tal, passam a receber um número elevado de alunos. De acordo com as pesquisas realizadas por Adão (2007, p. 280),

Já na década de 1940 o seu número é bastante elevado: representa cerca de $33 \%$ do número de escolas oficiais. $\mathrm{E}$, do mesmo modo, o número de alunos aumenta de ano para ano: entre 1934-1935 e 19401941 , conhece um acréscimo de perto de $270 \%$ e, até $1947-1948$, o aumento situa-se nos $171 \%$.

\footnotetext{
2 Postos de Ensino: Criados pelo Decreto n. 20.604, de 09 de dezembro de 1931 (PORTUGAL, 1931); Postos Escolares: Criados pelo Decreto n. 27.279, de 24 de novembro de 1936 (PORTUGAL, 1936).
} 
Essa transformação resultou em uma realidade na qual gradativamente o meio rural passou a contar com muitas instituições de ensino primário ${ }^{3}$. Portanto, o período que remonta aos anos de 1934 e se estende até o final da década de 1939 reveste-se de significados para a história da educação rural em Portugal, posto ter ocorrido naquele momento o anúncio de implementação de medidas institucionais com o objetivo de "solucionar" a baixa escolaridade nas regiões rurais. Certo é que, pelos motivos apresentados na sequência, foram medidas insuficientes para o problema.

Um primeiro aspecto a evidenciar da fragilidade dessas medidas recai sobre as características do próprio modelo de escola implantado no meio rural: os postos de ensino e depois postos escolares. Esses postos se organizavam em estabelecimentos de ensino isolados, multisseriados, unidocentes e mistos. Outro fator a caracterizar o ensino rural diz respeito a ausência, em muitas aldeias e propriedades rurais, de um lugar para a escola, uma vez que essa se confundia com a 'casa do professor' e assim era denominada. Ao tratar da memória e história dos edifícios escolares "no Portugal Rural”, Martins (2007, p. 326) tece as seguintes considerações:

Nas zonas rurais a escola foi o tempo do 'mestre-escola'. A casa onde vivia, único local para a prática do ensino, foi consecutivamente dependente dos apoios ou subsídios (subsídio literário). A relação 'casa do professor' e 'escola' foi estreita ao longo do século 19 e parte do século 20 , tendo influenciado a estrutura de organização escolar. A expressão ‘casa do professor', que ainda hoje é lembrada pela memória oral de suas gentes mais idosas acarretou a idéia de alojamento e sala organizada e apetrechada para receber os alunos às horas das lições.

Nessa casa do professor, a escola ganhava vida, existia como objeto social. Eram espaços pequenos, com salas multisseriadas e unidocentes, posto que regidas por um único professor. Mesmo afastadas dos centros urbanos, tendo que funcionar em locais improvisados e/ou adaptados,

3 Segundo informa Canário (2000, p. 122), “[...] a rede escolar do primeiro ciclo do Ensino Básico é formada ainda hoje, maioritariamente, por escolas de pequenas dimensões situadas em contexto rural". 
essas escolas deveriam cumprir um calendário e igualmente adotar um currículo próprio das instituições urbanas de ensino (ADÃO, 2007). Tanto no meio rural quanto no urbano não se exigiam diversidade de conteúdos e tampouco aprofundamento nos assuntos tratados. A esse propósito, ao pesquisarem a produção escrita de alunos e a conseqüente formação dos professores rurais em Cheleiros/Mafra (Lisboa), Aleixo e Alves (2007, p. 338) chegam às seguintes conclusões quanto à natureza dos conteúdos propostos para o ensino elementar no ano de 1938:

Demandava-se a simplificação do ensino primário, adequando-o às necessidades e interesses das classes populares. Preconizavase uma instrução primária abreviada e adaptada a um ensino de cariz estritamente popular esbatendo-se as fronteiras entre a escola e a vida. Para o ensino elementar $\left(1^{\mathrm{a}}, 2^{\mathrm{a}}\right.$ e $3^{\mathrm{a}}$ classes $)$ tinha primazia a obrigatoriedade de freqüência, e um programa de ensino elementaríssimo, que versava o 'ler, escrever, contar, compreensão dos factos simples da existência ambiente, educação moral e culto da pátria'.

Afora essa superficialidade dos conteúdos, da inexistência de um local próprio para o seu funcionamento, das salas unidocentes e multisseriadas, outros fatores caracterizavam a história da escola rural em Portugal, quais sejam: recursos públicos parcos e o auxílio da comunidade rural, de filantropos e/ou de beneméritos para o financiamento da construção de novos edifícios, reforma dos antigos e para as demais despesas requeridas para o funcionamento daquelas escolas; precariedade da oferta dessa modalidade de ensino e o descompasso entre a proposição de instrumentos legais de regulação e a insuficiência dos recursos públicos para os aplicarem. Em relação a esse último aspecto, de acordo com as análises de Martins (2007, p. 326),

Promulgou-se ao longo dos anos um 'corpus legislativo' regulador da construção escolar (escolas primárias), mas muitas vezes defasado das realidades concretas de cada região e, sobretudo, das zonas rurais (falta de verbas), o que foi impeditivo de se desenvolver um parque escolar dentro dos parâmetros aceitáveis. 
Assim, ainda que a legislação previsse a construção, reforma e manutenção dos prédios, faltavam verbas para aumentar o número de escolas, reformar os edifícios-escolas, ampliar a oferta de vagas nos estabelecimentos já existentes, investir na qualificação do professor dentre outras carências...

Embora em 20 de março de 1931 o Decreto-lei n. 19.502 houvesse estabelecido o projeto de "Melhoramentos Rurais", que previa construção, reforma e adaptação de escolas rurais, essa política não se concretizou plenamente, pois,

Como era habitual as Câmaras não dispunham de verbas, o povo das zonas rurais era pobre, crescia o desemprego e a miséria, índices elevados de analfabetismo e, por isso, as construções tardaram em concluir-se ou não se realizavam como estava estipulado legislativamente (MARTINS, 2007, p. 317).

Duas décadas após a promulgação desse Decreto, ainda persistiam os problemas relacionados aos espaços destinados às escolas rurais, tanto no que dizia respeito à situação dos edifícios quanto no que concernia à insuficiência de escolas para o atendimento da população rural. Segundo Martins, uma das soluções apresentadas pelo governo para sanar os problemas foi a criação da escola Tipo Rural, que consistia em edificar escolas com custos reduzidos. Para tanto, se programava um tempo menor para a execução da obra por meio do emprego de "elementos construtivos normalizados" e empregavam-se mão-de-obra com pouca especialização. Contudo, no dizer de Martins,

Esta construção apresentou vários inconvenientes, por exemplo, ao nível do abrigo junto à entrada, na instalação eléctrica que não funcionava por não haver electricidade, sem bebedouro por falta de água, alpendre sem muro de proteção, etc. (2007, p. 324).

Além da precariedade das edificações, a escassez de recursos implicava outros problemas para o desenvolvimento adequado do ensino rural, visto que condicionava também, e de maneira negativa, a qualificação da mão-de-obra docente. Dessa forma, a insuficiente qualificação dos 
professores que atuavam na escola rural agravou-se ainda mais nos 1930 com a criação dos postos de ensino para atender às necessidades de escolarização da população rural, pois nesses postos não se exigia do pessoal docente uma formação específica para o exercício do magistério. Segundo Carvalho (2011, p. 736), inicialmente exigia-se dos candidatos a regentes apenas a comprovação da idoneidade moral e intelectual, no entanto, devido aos inúmeros problemas decorrentes dessa situação, "[...] foi necessário publicar um novo decreto, com data de 28 de agosto de 1935, para se passar a exigir um exame de aptidão aos candidatos à regência dos referidos postos". Contudo, consoante ao que discutiremos nas páginas subsequentes, esse exame era superficial, sendo mínimo o nível dos conhecimentos aferidos.

\section{O Rural nos Editoriais da Escola Portuguesa}

Instituída pelo Decreto n. 22.369 (PORTUGAL, 1933), a EP era uma publicação da Direção Geral do Ensino Primário (DGEP), cujo propósito registrado em seu primeiro número, publicado em 11 de outubro de 1934, seria divulgar a doutrina pedagógica nacional e fornecer aos professores primários uma "técnica conveniente" ao desempenho de suas funções. A partir dessa missão, de 1934 a 1974, a EP publicou: legislação, notícias, fotografias, artigos, teses, discursos, conferências e palestras proferidas por autoridades educacionais e dirigidas aos professores primários. A sua periodicidade até 1958 era semanal, a partir de então tornou-se mensal. No período pesquisado, a revista era publicada todas as quintas-feiras ${ }^{4}$, sendo composta por cinco seções, assim distribuídas, segundo determinou a Secção X, do Artigo 174 do Decreto-Lei n. 22.369:

Art. 174. O Boletim do Ensino Primário Oficial é uma publicação periódica, com as seguintes secções:

1. ${ }^{a}$ Doutrinária em que serão insertos artigos segundo o objectivo referido no artigo 117.;

\footnotetext{
4 Segundo Guedes, essa periodicidade alterou-se em 1958, quando a revista tornou-se mensal (GUEDES, 1998).
} 


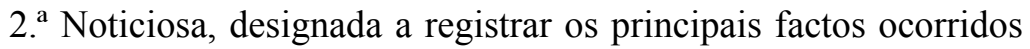
em Portugal ou no estrangeiro, respeitantes ao progresso e desenvolvimento do ensino primário;

3. a De legislação, na qual serão reproduzidos os textos legais, regulamentos e outros documentos que contenham preceitos ou instruções referentes ao ensino primário e à sua administração;

4. ${ }^{a}$ De despachos, que reproduzirá todas as resoluções respeitantes ao mesmo ensino que hajam sido insertos no Diário do Govêrno;

5. De estatística (PORTUGAL, 1933, p. 432).

Com vistas a perseguir o projeto de unidade nacional, propalado pelo Governo de Salazar, e de assegurar uma escola primária uniforme ${ }^{5}$, a revista manteve nesses cinco primeiros anos uma quase invariância em sua materialidade, visível na pouca alteração em sua diagramação, na distribuição dos conteúdos por suas seções e até mesmo na permanência de muitos de seus colaboradores. Há que se destacar, outrossim, a cuidadosa revisão pela qual passava o periódico, que evitava problemas na impressão, havendo pouquíssimos erros em suas três mil, oitocentos e quatro páginas distribuídas pelos duzentos e cinquenta e sete números.

\footnotetext{
5 Comouma das estratégias empregadas para unificar a escola, citamos o Decreto-Lei 27.279, de 24 de novembro de 1936, que preceituou no art. $2^{\circ}$. que a cada classe corresponderia um único livro e autorizou o Ministro da Educação Nacional a tomar as devidas providências para implementar essa determinação (PORTUGAL, 1936). A EP também contribuiu para efetivar esse propósito por meio da publicação de textos em que o assunto era discutido, tal como o excerto do editorial transcrito a seguir: "Na diversidade de movimento e de funções dos órgãos de cada corpo há sempre a unidade, em ordem ao fim para que foi criado. Emquanto (sic) essa unidade se mantiver, também êsse fim poderá ser atingido. Se ela se perder, o fim já não poderá ser atingido. Estão, pois, na boa razão os que defendem a unidade do pensamento e da acção dentro do corpo de serviços do ensino primário. Ser uno de pensamento e de acção com o órgão central desses serviços é ter a certeza de não viver a vida dos corpos estranhos ou parasitários pela certeza de bem viver" (LEAL, 1935, p. 743).
} 
QUADRO 01: A Escola Portuguesa e sua periodização em 5 anos

\begin{tabular}{|c|c|c|c|}
\hline Ano & Período & Números & Páginas \\
\hline I & 11 out. 1934 -26 set. 1935 & $01-51$ & 922 \\
\hline II & 10 out. 1935 - 24 set. 1936 & $52-102$ & 483 \\
\hline III & 07 out. 1936 - 30 set. 1937 & $103-153$ & 751 \\
\hline IV & 07 out. 1937 - 29 set. 1938 & $154-205$ & 995 \\
\hline V & 06 out. 1938 - 28 set. 1939 & $206-257$ & 653 \\
\hline \multicolumn{2}{|l}{ TOTAL DE PÁGINAS } & 3.804 \\
\hline
\end{tabular}

Fonte: A autora. Dados extraídos da revista Escola Portuguesa, 1934-1939.

A opção por privilegiar os editoriais decorreu da compreensão de que esse gênero jornalístico, por expressar a opinião oficial do mantenedor do periódico e, portanto, por se constituir no locus privilegiado para se tratar os assuntos em destaque na sociedade em um dado momento ${ }^{6}$, possibilitaria, por meio da análise de seus conteúdos, aquilatar o espaço reservado ao ensino primário rural pela EP e, portanto, apreender o papel que esse ensino desempenharia no âmbito do projeto de renovação da escola portuguesa segundo os princípios do Estado Novo.

A metodologia de trabalho consistiu primeiramente na leitura de todas as seções da EP dos cinco primeiros anos de publicação (1934 a 1939), inclusive o campo destinado à publicação dos Diários do Governo com as suas respectivas legislações. Após essa etapa, retomamos a leitura apenas dos editoriais e a partir dessa atividade traçamos o perfil desse gênero do jornalismo no que concerne aos temas e à autoria.

Relativamente aos temas, sem a pretensão de discriminar os duzentos e cinquenta e sete números, os classificamos em quatro categorias, a saber: Educação Nacional, Orientação Didática, Discursos e Outros. Em Educação Nacional agrupamos os seguintes temas: papel do professor, valores filosóficos da educação e da pedagogia, rituais cívico-patrióticos, legislação, dever da escola, Mocidade Portuguesa, apologia ao Estado

\footnotetext{
6 Ainda que, segundo Melo (2003), o conceito de editorial tenha sofrido alterações devido às transformações perpassadas na sociedade e, por conseguinte, nos meios de comunicação, acreditamos que a definição mais tradicional de editorial representa em parte as características desse gênero jornalístico no âmbito da EP.
} 
Novo, anticomunismo. No segundo conjunto alocamos os assuntos que diziam respeito à discussão metodológica sobre como ensinar as disciplinas e os seus respectivos conteúdos; os castigos; os exames; a escola ativa e o uso dos livros didáticos na escola primária. Inserimos no terceiro grupo todo o conteúdo que dizia respeito a discursos, fossem proferidos pelo General Carmona, Presidente; por Oliveira Salazar, Chefe do Conselho de Ministros, pelo Ministro da Educação Nacional e demais autoridades. Por fim, em Outros encontram-se aqueles conteúdos que se afastam das classificações anteriores.

O resultado obtido está sintetizado no quadro a seguir, cuja leitura permite concluir o predomínio nos editoriais, com $56,8 \%$ de presença em relação aos demais, dos temas relacionados à Educação Nacional. Em segundo lugar aparecem os discursos, com 17,5\% de incidência. Considerando que esses discursos sempre eram proferidos por autoridades diretamente ligadas ao governo, podemos concluir que, de fato, o tema privilegiado dos editoriais consistia na promoção da ideologia que deveria perpassar a escola primária e dar sustentação à consolidação do Estado Novo.

QUADRO 02: Temas Discutidos nos Editoriais

\begin{tabular}{|c|c|c|c|c|c|}
\hline \multirow{2}{*}{$\begin{array}{c}\text { ANO DE } \\
\text { PUBLICAÇÃO }\end{array}$} & \multirow{2}{*}{ EDITORIAIS } & \multicolumn{4}{|c|}{ CATEGORIAS } \\
\cline { 3 - 6 } & & $\begin{array}{c}\text { Educação } \\
\text { Nacional }\end{array}$ & Discursos & $\begin{array}{c}\text { Orientação } \\
\text { Didática }\end{array}$ & Outros \\
\hline I & 51 & 28 & 02 & 11 & 10 \\
\hline II & 51 & 29 & 04 & 10 & 08 \\
\hline III & 52 & 34 & 10 & 04 & 04 \\
\hline IV & 51 & 28 & 12 & 06 & 05 \\
\hline V & 52 & 27 & 17 & 08 & 00 \\
\hline Total & 257 & 146 & 45 & 39 & 27 \\
\hline \% & $100 \%$ & $56,8 \%$ & $17,5 \%$ & $15,2 \%$ & $10,5 \%$ \\
\hline
\end{tabular}

Fonte: A autora. Dados extraídos da revista Escola Portuguesa,1934-1939. 
No que diz respeito às assinaturas dos editoriais, ainda que nos manuais do jornalismo opinativo predomine como definição desse gênero a impessoalidade, ou seja, a não assinatura da matéria (MELO, 2003), em nossa pesquisa mantivemos a classificação dos editoriais segundo as assinaturas por ter sido essa uma particularidade da EP. Entretanto, a nossa preocupação não consistiu em discriminar os autores dos editoriais pelos respectivos nomes, mas, sim, pelos cargos ou funções ocupados no governo. QUADRO 03: Autoria dos Editoriais

\begin{tabular}{|c|c|c|c|c|c|c|}
\hline & & \multicolumn{5}{|c|}{ COLABORADORES } \\
\cline { 3 - 7 } ANO & EDITORIAIS & Inspetores & Não Assinado & Professores & $\begin{array}{c}\text { Diretor } \\
\text { GEP } \mathbf{e} \\
\text { Adjunto } \\
\text { Diretor }\end{array}$ & Outros \\
\hline I & 51 & 25 & 02 & 08 & 03 & 13 \\
\hline II & 51 & 37 & 02 & 02 & 02 & 08 \\
\hline III & 52 & 15 & 07 & 12 & 03 & 15 \\
\hline IV & 51 & 02 & 30 & 02 & 01 & 16 \\
\hline V & 52 & 07 & 22 & 02 & 02 & 19 \\
\hline Total & 257 & 86 & 63 & 26 & 11 & 71 \\
\hline$\%$ & $100 \%$ & $33,5 \%$ & $24,5 \%$ & $10,1 \%$ & $4,3 \%$ & $27,6 \%$ \\
\hline
\end{tabular}

Fonte: A autora. Dados extraídos da revista Escola Portuguesa, 1934-1939.

*Diretor Geral do Ensino Primário

Dessa forma, pela leitura do Quadro 03, constatamos a predominância dos Inspetores no rol de autores dos editoriais, com 33,5\%, seguidos por Outros, com $27,6 \%$, em cuja categoria inserimos os diretores dos distritos escolares, os médicos, o Ministro da Educação. No entanto, se considerarmos que os editoriais não assinados - um total de $24,5 \%$ na EP - são assumidos pelo órgão responsável pelo periódico e levando em conta que a EP era um boletim da DGEP, deveremos incluir também aqueles 
assinados pelo Diretor Geral do Ensino Primário e por seu Diretor Adjunto, que somaram $4,3 \%$, perfazendo assim um percentual de $28,8 \%$.

Esse fato pode ser justificado em função do contexto ditatorial do período e consequentemente pelas iniciativas da regulamentação da escola primária e de controle sobre os seus agentes. A incidência maior dos "editoriais dos inspetores" verifica-se no primeiro e segundo anos da EP, ou seja, no período de 1934 a meados de 1937, em parte coincidente com o momento de 1926 a 1936 quando, no dizer de Correia, começa a se consolidar uma dada política educativa, cuja orientação se pautava nos esforços para, ao mesmo tempo, extinguir as marcas do regime anterior e erigir as bases do Estado Novo. Nesse contexto, teria havido o predomínio da "Imposição de uma administração centralista e autoritária do sistema educativo, através do reforço dos mecanismos de inspecção e controlo mais rígido dos corpos docentes e discentes [...]" (CORREIA, 1998, p. 75).

Após essa caracterização mais geral dos editoriais da EP, e com o objetivo de tornar mais próximo o problema da pesquisa, estabelecemos dois grupos temáticos de análise dentro dos quais distribuímos dezenove categorias. No primeiro, denominado "Rural", construído a partir de nosso tema de pesquisa, inserimos: Agrícola/Agricultura, Aldeia, Campo, Ensino/ Escola Rural, Mundo/Vida Rural, Postos de Ensino, Postos Escolares, Regentes, Rural (Quadro 04); no segundo, "Projeto Educacional do Estado Novo", alocamos: Analfabeto/Analfabetismo, Ativa (Escola), Cristão/ Cristã/Cristo, Disciplina, Escola/Ensino Primário, Família, Moral, Nação/Nacional/Nacionalista, Pátria e Professor (Quadro 05).

A partir dessa classificação, a primeira constatação da análise incidiu sobre o quase silenciamento dos editoriais a respeito da escola instalada no meio rural, fosse essa posto de ensino em um primeiro momento, fosse posto escolar a partir de 1936. Conforme se pode observar no Quadro 04 a seguir, das nove categorias elencadas como representativas do meio rural e da escola aí instalada, o total de menção a cada uma delas nos editoriais é insignificante, considerando duzentos e cinquenta e sete números e, portanto, o mesmo total de editoriais publicados no período. Com exceção de aldeia, citada em 9,3\% dos editoriais, as demais não 
atingem nem 5\%. Campo é citado em nove (3,5\%), Agrícola/Agricultura só aparecem em seis números (2,3\%), Postos Escolares em nove (3,5\%), Regentes em sete (2,7\%), Rural em seis (2,3\%), Ensino/Escola Rural em cinco (1,9\%), Postos de Ensino em quatro (1,5\%), Mundo/Vida Rural não aparece em nenhum.

QUADRO 04: Escola Portuguesa e o Rural

\begin{tabular}{|c|c|c|c|c|c|c|c|}
\hline $\begin{array}{c}\text { Ano de } \\
\text { Publicação }\end{array}$ & I & II & III & IV & V & Total & $\%$ \\
\hline $\begin{array}{c}\text { Total de } \\
\text { Editoriais }\end{array}$ & 51 & 51 & 52 & 51 & 52 & 257 & $100 \%$ \\
\hline Categorias & \multicolumn{7}{|c|}{ Número de Editoriais em que a Categoria é citada } \\
\hline Aldeia & 02 & 07 & 04 & 07 & 04 & 24 & $9,3 \%$ \\
\hline Campo & - & 03 & 02 & 03 & 01 & 09 & $3,5 \%$ \\
\hline Postos Escolares & - & - & 01 & 03 & 05 & 09 & $3,5 \%$ \\
\hline Regentes (Postos) & - & - & 02 & 02 & 03 & 07 & $2,7 \%$ \\
\hline $\begin{array}{c}\text { Agrícola/ } \\
\text { Agricultura }\end{array}$ & - & 03 & - & 02 & 01 & 06 & $2,3 \%$ \\
\hline Rural & 01 & 04 & - & - & 01 & 06 & $2,3 \%$ \\
\hline $\begin{array}{c}\text { Ensino/Escola } \\
\text { Rural }\end{array}$ & - & 02 & 01 & 01 & 01 & 05 & $1,9 \%$ \\
\hline Postos de Ensino & - & 02 & 01 & 01 & - & 04 & $1,5 \%$ \\
\hline Mundo/Vida Rural & 0 & 0 & 0 & 0 & 0 & 0 & 0 \\
\hline
\end{tabular}

Fonte: A autora. Dados extraídos da revista Escola Portuguesa, 1934-1939.

O destaque deve ser conferido à categoria Aldeia que é mencionada em vinte e quatro editoriais. Contudo, nenhum dizia respeito especificamente à escola, aos postos escolares ali instalados ou aos regentes. $\mathrm{O}$ contexto em que a categoria aparece relaciona-se mais à necessidade de difundir o cultivo do modo de vida rural e reforçar na população rural os bons hábitos, como, por exemplo, no editorial em que se discute o afastamento dos livros ao qual está submetida a população rural e defende a criação de 
bibliotecas para estimular a leitura (LER..., 1934). Outro exemplo pode-se buscar no texto que classifica os professores em dois tipos: os benéficos e os que se aliam aos elementos menos bons; ao fazer essa distinção, o autor menciona o papel que ambos os tipos de professores exercem nas aldeias por onde passam (RAMALHO, 1934). No ano seguinte, antes de anunciar a série de artigos que a revista publicaria acerca da apicultura, Graça (1935) ocupa 4/5 de um editorial a denunciar os "maus costumes" do homem rural e a rusticidade de seu modo de vida, exortando o leitor para a urgente necessidade de transformar a mocidade rural a fim de evitar o êxodo. Em outro editorial do mesmo ano, o subinspetor escolar do distrito de Castelo Branco, Gomes dos Santos, comenta os maus usos da língua, sobretudo no que diz respeito à ortografia, critica jornais que publicam textos com erros ortográficos e menciona tabuletas de aldeias com o mesmo problema (SANTOS, 1935). Felismina de Oliveira, Inspetora dos serviços de orientação pedagógica, ao ver as crianças a caminho da escola, divaga sobre as precárias condições de algumas e comenta a situação da criança da aldeia:

Por compreensível associação de ideias, passam agora pelo meu espírito tantas crianças quase nuas, de maos ulceradas pelas frieiras, que no inverno passado encontrei pelas escolas de diversas aldeias da Beira. E penso que, se 'não se pode pregar moral a estômagos vazios' - também se não pode a ensinar a escrever a mãozita enregelada de uma criança (OLIVEIRA, 1936, p. 128).

Relativamente aos Postos de Ensino, somente no Ano II há referência a essas instituições. No entanto, são citadas de forma genérica, apenas para relatar as festividades escolares realizadas em comemoração ao $1^{\circ}$ de dezembro (FESTA, 1936). Em agosto do mesmo ano, os postos voltam a ser mencionados quando o editorial comenta a falta de frequência em algumas escolas, aponta as causas e apresenta soluções para o problema; esse editorial menciona os postos apenas para dar exemplo de como algumas localidades que têm escolas vazias não comportam sequer uma escola dessa natureza (PORTUGAL, 1936). No ano III, os postos retornam ao editorial, porém o tema dizia respeito às férias e o papel de educador 
que o professor sempre deverá exercer, mesmo em seus momentos de descanso (EM TODA, 1937). No ano seguinte de publicação da revista, o editorial cita os postos ao reproduzir o texto da proposta de lei de Reforma do Ensino Primário (REFORMA, 1937).

Os Postos Escolares são citados em nove editoriais, sendo que a sua primeira menção somente ocorrerá em 1937, no ano seguinte ao de sua criação, no mesmo editorial que citou as regentes pela primeira vez, conforme informaremos a seguir (A VISITA, 1937). Na sequência, os postos são citados no editorial na proposta de lei de Reforma do Ensino Primário (REFORMA, 1937). No mesmo ano voltam a figurar no editorial que trata da abertura do ano escolar e compara o trabalho do educador com o do semeador sem, no entanto, abordar a rotina dos postos escolares de forma particularizada (RECOMEÇANDO, 1937). Ao comentar as visitas às escolas feitas pelo Ministro da Educação Nacional - Carneiro Pacheco cita os postos escolares, mas apenas para referir-se às festas escolares que são realizadas em todo o país (AINDA, 1938). Por fim, Carneiro Pacheco no discurso proferido em homenagem aos dez anos transcorridos desde a posse de Salazar como Ministro das Finanças cita os postos em alusão ao espaço onde se ensinava o povo a ler (DISCURSO, 1938).

A quase ausência dos postos de ensino e postos escolares nos editoriais da EP nos anos de 1930 contrasta com o papel desempenhado por essas instituições na solução do problema dos altos índices de analfabetismo no país no mesmo período. Essa importância pode ser aferida pelo número crescente dos postos que, conforme apontamos anteriormente, atingiam no início dos anos de 1940 um percentual de 33\% do total das escolas primárias oficiais em Portugal. Ao ignorá-los, a EP esquivava-se de tornálos objeto de estudo, ou, no limite, evitava divulgar o que já parecia estar consolidado como fenômeno social.

A regente ${ }^{7}$ - como denominação do profissional docente dos postos de ensino e dos postos escolares - só é mencionada pela primeira vez quando se comenta a visita que o Ministro da Educação realizou às escolas e aos postos escolares no Algarve (VISITA, 1937). Outra vez foi mencionada a propósito de balanço do ano letivo que havia terminado e

\footnotetext{
7 Nos editoriais acima mencionados a referência é sempre feita à regente no gênero feminino. Acreditamos que essa situação se explique em função de que $92 \%$ desses docentes eram do sexo feminino (RIAS, 1997).
} 
de uma recapitulação da legislação que regulamentou o funcionamento da escola primária, sem, no entanto, ter sido acompanhada de discussão e/ ou comentário sobre as condições de trabalho dessas profissionais (DO ANO, 1937). No ano seguinte menciona-se novamente a regente apenas para se referir à necessidade de se conhecer os programas escolares (É NECESSÁRIO, 1937). Posteriormente, essas profissionais figuram em alguns artigos da proposta de lei de reforma do ensino primário já referida (REFORMA, 1937).

Adão (1984) informa que o percentual dos regentes em relação aos professores primários era de 7,7\% no período de $1934-1935,15,9 \%$ de 1936 a 1937 e de $19,8 \%$ de 1938 a 1939; diante desse crescimento, pergunta-se: quais seriam as explicações para o fato de os editoriais da EP ignorarem as regentes? Uma das respostas poderá ser encontrada se atentarmos para o seu estatuto sócio-profissional caracterizado pelo desprestígio, pois, conforme informamos, as regentes ingressavam na profissão por meio de nomeação, cujo requisito inicial era apenas atestado de idoneidade moral. Segundo Carvalho (1983, p. 736): "O autor do presente livro teve conhecimento [...] de que um pretendente a regente escolar declarara, ao ter que assinar o auto de posse, que não sabia escrever."

A situação não se alterou substacialmente mesmo, a partir de 1935, quando se passou a exigir aprovação dos candidatos em provas de aptidão. Os relatórios dos presidentes dos júris desses processos seletivos, dois excertos transcritos a seguir, demonstram o nível pífio de exigência das provas e, ainda assim, os resultados insuficientes apresentados pelos candidatos: "Dos 35 que realizaram a prova escrita, apenas 10 foram admitidos à oral. Os restantes tiveram de ser excluídos, apesar da facilidade do ponto" (NOTÍCIA, 1936, p. 26). Um ano antes desse exame o problema já havia sido verificado por outro presidente do júri:

Pelo exame das provas se verifica a insuficientíssima preparação dos candidatos, em especial nos conhecimentos mais rudimentares da língua pátria. Em todas as provas da maioria dos candidatos se nota o desconhecimento da grafia e do significado de palavras vulgares. As provas de história, corografia e ciências histórico-naturais demonstram absoluto desconhecimento da matéria, ou completa confusão de conhecimentos em tempo adquiridos (VIANA, 1935, p. 12). 
Além dessas categorias, buscamos também a palavra Rural e a encontramos em seis editoriais, sendo que, em 1935, o inspetororientador, Ricardo Bensaúde, escreveu sobre a importância do escotismo para promover hábitos saudáveis na mocidade escolar e, embora tenha mencionado a população rural, não aludiu à escola instalada no meio rural (BENSAÚDE, 1935). Em outubro do mesmo ano, conforme apresentado na categoria aldeia, o rural aparece como espaço cujos costumes e hábitos de sua população necessitam de reforma (GRAÇA, 1935). Almodôvar (1935), Professor do Liceu Normal de Lisboa, ao caracterizar o trabalho feito na Alemanha para a formação da juventude hitlerista, menciona o rural e ressalta as iniciativas para atrair os jovens ao campo e ao trabalho agrícola. Em outro editorial, o Ministro da Educação Nacional, em discurso proferido a propósito da posse da junta central da Obra das Mãis pela Educação Nacional, cita o embelezamento do rural ao discorrer sobre um dos objetivos dessa iniciativa (OBRA, 1936). A categoria só volta a figurar quando, ao apresentar as finalidades da educação, o editorial faz uma oposição entre a vida urbana e a rural, comenta o êxodo rural e discute os meios de o combater (REFLEXÕES, 1937). Deve-se destacar que é nesse editorial que aparece claramente e pela primeira vez uma apologia aos costumes do povo que habita o meio rural em detrimento dos citadinos, pois, até então, conforme salientamos, citava-se o meio rural como um espaço carente de reforma no modo de vida de seus habitantes e de higienização dos seus costumes. Por fim, o rural retorna no texto da proposta de lei de reforma do ensino primário (REFORMA, 1937).

A análise possibilita concluir que, nesses cinco primeiros anos de publicação da EP, a idealização da vida rural e do modo de vida dos habitantes do meio rural - tópicos da propaganda do Estado Novo (MÔNICA, 1978) - ainda não eram os temas preferencialmente publicados, pois, se atentarmos para as categorias Agrícola/Agricultura, Aldeia, Campo, Mundo/Vida Rural e Rural (Quadro 04), que remetem a essa particularidade, constataremos que a sua presença era insignificante nas páginas dos editoriais. Mesmo a categoria Aldeia, cuja incidência é mais significativa, não atinge nem $10 \%$ dos editoriais. Além desse aspecto, de acordo com o já informado, subjaz aos primeiros editoriais em que essa categoria é abordada uma representação do mundo rural como locus do atraso e da falta de educação de seus moradores. 
Ainda atinente ao Quadro 04, podemos aquilatar que, aliada à inexpressiva presença da vida rural, a escola rural é quase silenciada. Ensino/Escola Rural, Postos de Ensino, Postos Escolares e Regentes são categorias cuja incidência de citação nos editoriais ainda é inferior àquelas concernentes à vida rural, comentadas anteriormente.

Ao contrário desse primeiro grupo de categorias referente ao espaço rural e à escola rural nele instalado, o segundo tema, cujas categorias denotam o caráter ideológico do regime e os pressupostos que orientariam uma dada política ditatorial para a organização e funcionamento da escola primária, está presente de forma reiterada nos editoriais, consoante se depreende do quadro a seguir.

QUADRO 05: Escola Portuguesa: Projeto Educacional do Estado Novo

\begin{tabular}{|c|c|c|c|c|c|c|c|}
\hline $\begin{array}{c}\text { ANO DE } \\
\text { PUBLICAÇÃO }\end{array}$ & I & II & III & IV & V & Total & $\%$ \\
\hline $\begin{array}{c}\text { TOTAL DE } \\
\text { EDITORIAIS }\end{array}$ & 51 & 51 & 52 & 51 & 52 & 257 & $100 \%$ \\
\hline CATEGORIAS & \multicolumn{2}{|c|}{ Número de Editoriais em que é mencionada a Categoria } \\
\hline $\begin{array}{c}\text { Nação/Nacional/ } \\
\text { Nacionalista }\end{array}$ & 28 & 19 & 26 & 25 & 32 & 130 & $50,6 \%$ \\
\hline $\begin{array}{c}\text { Escola/Ensino } \\
\text { Primário }\end{array}$ & 30 & 24 & 26 & 18 & 21 & 119 & $46,3 \%$ \\
\hline Pátria/Patriotismo & 24 & 14 & 22 & 21 & 30 & 111 & $43,1 \%$ \\
\hline Professor Primário & 30 & 20 & 25 & 17 & 19 & 111 & $43,1 \%$ \\
\hline Moral & 10 & 14 & 11 & 22 & 25 & 82 & $31,9 \%$ \\
\hline $\begin{array}{c}\text { Cristão/Cristã/ } \\
\text { Cristo }\end{array}$ & 11 & 14 & 14 & 14 & 15 & 68 & $26,4 \%$ \\
\hline Família & 07 & 07 & 08 & 14 & 17 & 53 & $20,6 \%$ \\
\hline Disciplina & 03 & 07 & 06 & 09 & 10 & 35 & $13,6 \%$ \\
\hline $\begin{array}{c}\text { Analfabeto/ } \\
\text { Analfabetismo }\end{array}$ & 01 & 03 & 03 & 06 & 03 & 16 & $6.2 \%$ \\
\hline Ativa (Escola) & 06 & 03 & 00 & - & 04 & 13 & $5 \%$ \\
\hline
\end{tabular}

Fonte: A autora. Dados extraídos da revista Escola Portuguesa, 1934-1939. 
A incidência dessas categorias no conjunto dos editoriais analisados explica-se em função do contexto político vigente no país no período em questão: o regime autoritário, centralizador do Estado Novo. Fortemente orientado para a promoção, via escola primária, dos ideais nacionalistas, o Governo, por meio da DGEP, conformou a EP a fim de torná-la um dos mais eficientes e diretos canais de doutrinação, propaganda e comunicação. Nas páginas da revista, sobretudo em seus editoriais, estavam impressas as orientações do modelo de escola primária a ser implantado e dos preceitos educativos que a conduziriam. Nação, pátria, moral, cristão, família eram as senhas que a escola primária, por meio de seus professores, deveria empregar para servir aos propósitos da "renovação" pretendida. Daí se compreende que:

A formação educativa desenvolvida pelo Estado Novo é, nas suas premissas, mais orientada por uma perspectiva sociologista do que psicologista. O seu objectivo não é a promoção das capacidades de expressão pessoal do educando, mas a sua disponibilização em relação à nação, à pátria. Daí que, a função socializadora da escola primária se oriente para a promoção dos meios centralizadores do orgulho nacional [...] (CORREIA, 1998, p. 71).

E como o analfabeto e o próprio analfabetismo conspurcavam esse "orgulho nacional" a EP esquivava-se de tocar nesse assunto. Num país cuja taxa de letrados atingia apenas $40 \%$ da população em 1930 (RAMOS, 1998), somente 6,2\% dos editoriais citaram os analfabetos ou o analfabetismo.

Por fim, da análise comparada dos dois quadros, depreende-se que a Revista mais que um mero veículo de comunicação entre a DGEP e os professores primários, mais ainda que um manual de formação didática com vistas a orientar a ação pedagógica - haja vista que, segundo o QUADRO 2, os textos de cunho metodológico, ou de orientação didática, perfazem apenas um percentual de $15,2 \%$ no conjunto dos temas dos editoriais -, era um vigoroso veículo de propaganda do Estado Novo.

A análise dos cinco primeiros anos da EP e, em particular, a leitura atenta dos conteúdos dos editoriais publicados nesse período e 
a frequência com que são empregadas as categorias, atesta o caráter ideológico do periódico e a sua contribuição para educar, conformar e moldar os professores primários segundo um projeto de sociedade e de escola calcado nos pressupostos nacionalistas que sustentavam o governo ditatorial português. Com isso, a EP consolidou-se como um "monumento" educativo do professorado primário em Portugal.

A Revista seria o meio, o instrumento, o caminho colocado à disposição sobretudo do professor primário, para atingir a meta cobiçada. Significa então que a escola nacional era um meio utilizado pelo Regime para o triunfo da Revolução Nacional, ou seja a escola era um dispositivo útil e necessário para a edificação de uma nova mentalidade que auxiliaria a construção do novo Portugal (GUEDES, 1998, p. 21).

No aspecto mais geral, concluímos que os editoriais da EP, embora mantivessem como traço de unidade a natureza promocional, visível nos temas sempre laudatórios ao Estado Novo, caracterizaram-se por um relativo ecletismo no que diz respeito à sua topicalidade, conteúdo e estilo ${ }^{8}$. Com relação à topicalidade, os editoriais foram tanto preventivos, ativos, quanto consequentes; no que diz respeito aos conteúdos, deparamo-nos

\footnotetext{
${ }^{8}$ Segundo as definições de Beltrão (1980), os editoriais podem ser classificados segundo a sua morfologia, topicalidade, conteúdo, estilo e natureza. Melo (2003, p. 110-111), ao analisar os editoriais presentes na imprensa brasileira, completa essa classificação ao especificar os componentes de cada um desses elementos classificatórios, a saber: "Quanto à morfologia, os editoriais que aparecem na imprensa brasileira se diferenciam em: artigo de fundo (editorial principal), suelto (pequena análise sobre um fato da atualidade) e nota (registro ligeiro de uma ocorrência, antecipando suas consequências ao leitor). A topicalidade produz três espécies de editoriais: preventivo (focalizando aspectos novos que podem produzir mudanças), de ação (apreendendo o impacto de uma ocorrência) e de consequência (visualizando repercussões e efeitos). No que se refere ao conteúdo, temos: informativo (esclarecedor), normativo (exortador) e ilustrativo (educador). O estilo pode sugerir duas espécies: o intelectual (racionalizante) o emocional (sensibilizante). Finalmente, quanto à natureza, o editorial se divide em: promocional (coerente com a linha da empresa), circunstancial (oportunista, imediatista) e polêmico (contestador, provocador)." Embora essa classificação tenha sido empregada para os editoriais presentes na imprensa brasileira, empregamo-la para análise dos editoriais da EP por considerarmos que compreendem uma definição abrangente do editorial enquanto um dos gêneros do jornalismo opinativo e que, por isso, pode ser aplicada em outros contextos.
} 
com editoriais informativos, de cunho esclarecedor, com outros normativos e, por fim, com os ilustrativos ou educativos.

\section{Além dos editoriais... E a escola rural?}

Embora o rural não tenha figurado nos editoriais, destacamos da EP duas colaborações onde a escola rural era comentada, a saber: "Realidades" e "Apontamentos de higiene das escolas primárias". "Realidades" era o nome de uma crônica publicada pela inspetora Felismina Oliveira em alguns números da $\mathrm{EP}$ durante $\mathrm{o} \mathrm{V}$ ano, cujo assunto referia-se às visitas de inspeção realizadas nas escolas e nos postos escolares. A autora usou o espaço para descrever a situação em que se encontravam esses estabelecimentos ao visitá-los, e a partir do relato pode-se tecer o perfil das escolas rurais. No que concerne às vias de acesso até os postos escolares, por exemplo, a inspetora comentou em um dos relatórios as precárias condições da estrada que a conduziu até a Aldeia de destino (OLIVEIRA, 1939a); em outra crônica mencionou o interior da sala de aula, os problemas com a iluminação, informou a insuficiente qualificação da regente e comentou a falta de elegância das alunas no gesto de saudação (OLIVEIRA, 1939b); em outra crônica registrou a informação da regente sobre os seus gastos pessoais na compra de material didático para o ensino e para os próprios alunos (OLIVEIRA, 1939c). Embora não sejam muitas, nessas crônicas encontram-se informações detalhadas das escolas rurais e dados sobre as práticas das regentes.

Os "Apontamentos de higiene das escolas primárias" eram minuciosos relatórios elaborados e assinados pelo médico José Lopes Dias publicados pela EP. Como o nome revela, o seu conteúdo dizia respeito à investigação feita in loco das condições de funcionamento das escolas primárias portuguesas, tanto as urbanas quanto as rurais. Ainda que esses apontamentos, diferentemente dos escritos de Felismina Oliveira, não fizessem alusão ao retrato interno do funcionamento dos postos e nem às práticas das regentes, por se tratar de inquérito há muitas informações detalhadas da infraestrutura das escolas, tais como: condições do terreno, conservação dos prédios, distribuição dos espaços externo e interno, total de alunos, saúde dos alunos, situação social, dentre outros. No apontamento a seguir existe a seguinte descrição: 
99) Escola mixta de Aldeia de S. Francisco de Assis, em casa adAptada, de solo úmido, vaga desde 1934, sem condições higiénicas para o funcionamento da classe, com sessenta e três alunos.

100) Escola mixta de Aldeia de Souto, em casa adaptada, de solo arenoso e sêco, com estábulos, estrumeiras e tabernas a menos de 20 metros de distância, orientação NE., desabrigada dos ventos, uma divisão com área de 25 metros quadrados, a cubagem de 70 metros cúbicos, iluminação bilateral por duas janelas a L. e W. com área de $1 \mathrm{~m} 2,92$, a freqüência de trinta e cinco alunos.

De luz e cubagem insuficientes, muito quente no verão, muito fria no inverno, não tem cantina, lavatórios, recreios nem latrinas.

Quatro dos seus alunos vivem a dois quilómetros, oito a três quilómetros, um deficiente ocular, cinco são atardados, e quási todos merendam insuficientemente e andam mal agasalhados. (...). (DIAS, 1937, p. 17).

Pela leitura desses apontamentos se depreende um pouco as "realidades" dos postos escolares. Contudo, tanto os apontamentos do médico José L. Dias quanto as crônicas de Felismina Oliveira foram publicados em poucos números da EP e a presença do rural encontrada nos registros de ambos os autores não se repetia nas demais seções, onde o assunto, tal qual o verificado nos editoriais, não recebia destaque.

Analisamos, por exemplo, as muitas imagens publicadas na revista no período pesquisado e também os temas das conferências ministradas aos professores primários. Com relação ao primeiro aspecto, composto por fotografias de prédios escolares, professores e alunos, autoridades da administração escolar, comemorações escolares de cunho cívico-religiosas, dentre outras, o conjunto inconográfico presente na EP diz respeito majoritariamente à história da educação escolar urbana. Localizamos apenas três imagens fotográficas em cujas legendas constam menções a personagens da escola rural: na primeira, uma fotografia da regente com os seus alunos sentados na parte externa do posto escolar, há a seguinte identificação: "Alunos do pôsto de ensino de Atalaia, concelho de Lagos, com a sua regente" (DOCUMENTOS, 1935, n. p.); a segunda e terceira fotografias, publicadas em uma mesma página, repetem o tema e se podem ler nas legendas: "A regente e alunos do pôsto de ensino de 
Quartos, concelho de Loulé" e "A regente e alunos do pôsto de ensino de Maritendas, concelho de Loulé" (A ESCOLA, 1936, n. p.). Nos demais anos de publicação não foi identificada nenhuma fotografia que contivesse identificação de postos escolares, regentes ou alunos do meio rural.

As conferências dirigidas aos professores primários foram amplamente noticiadas nas páginas da EP nos I e II; primeiro eram divulgados os temas, os palestrantes, local de realização e datas. Posterior e gradativamente a revista publicava os textos integrais de alguns desses eventos. Segundo circular enviada às seções dos distritos escolares e publicada em 26 de setembro 1935, as conferências eram atividades promovidas aos professores primários e se caracterizavam pela promoção de trabalhos de duas naturezas distintas, a saber:

a) Discutem-se teses, de assuntos pedagógicos ou didácticos, cujas conclusões se sujeitam a discussão;

b) Desenvolvem-se, em prelecções, assuntos que interessam a preparação cultural dos professores - acêrca dos quais não há discussão (...).

12. (...) em todas as conferências haverá também uma sessão destinada à recapitulação, explanação e esclarecimento de dúvidas da doutrina das instruções de orientação pedagógica (SERVIÇOS, 1935a, p. 920).

Uma iniciativa de formação continuada oferecida aos professores e, notadamente, um instrumento ideológico da DGEP a serviço da "pedagogia ditatorial", segundo se depreende da circular supra, essas conferências ocorriam em ocasiões solenes quando, nos conselhos que as sediavam, eram apresentados os trabalhos escolares, recitais de poesias, corais infantis e outras atividades. Esses momentos deveriam representar um marco significativo da ação do governo em prol do desenvolvimento da escola primária e da própria visibilidade dessa ação.

Ressaltamos que nos meses de dezembro/1934, fevereiro, abril a junho de 1935, de um total de 99 conferências realizadas em pelo menos três regiões de Portugal (norte, sul e Alentejo) nenhuma teve como tema a escola rural ou sociedade rural. Nos períodos de 13 a 19/01/1935 e 27/01/1935 a 09/02/1935, das conferências realizadas em Viseu, apenas duas tiveram como tema o rural, a saber: "A ação do professor na Aldeia" e outra tratou 
das "Festas escolares e sua influência nos meios rurais (SERVIÇOS, 1935b, p. 295)." De novembro de 1936, até o mês de junho de 1937, computamos mais um total de duzentos e sessenta e cinco conferências e dessas apenas dez trataram da escola rural, conforme quadro a seguir:

QUADRO 06: Temas das Conferências

\begin{tabular}{|l|}
\hline \multicolumn{1}{|c|}{ TÍTULO/TEMA } \\
\hline $\begin{array}{l}\text { A escola com um só professor e quatro classes perante os preceitos da pedagogia } \\
\text { moderna. Vantagens que oferece. Condições dum bom andamento progressivo e } \\
\text { corrente do respectivo trabalho }\end{array}$ \\
\hline Como ensinar agricultura nas escolas \\
\hline A ação da escola nos meios rurais \\
\hline Ambiente social da escola rural portuguesa \\
\hline $\begin{array}{l}\text { Influência do professor dos meios rurais na formação moral das famílias e atitudes } \\
\text { adequadas à sua consecução }\end{array}$ \\
\hline A escola e agricultura: o horto escolar, como organizá-lo. \\
\hline Como ensinar agricultura na escola \\
\hline
\end{tabular}

Fonte: A autora. Dados extraídos da revista Escola Portuguesa, 1934-1939.

Após analisar os assuntos debatidos nas conferências, concluímos que mais uma vez a escola rural permaneceu à margem das discussões relativas à escola primária e a formação de seus professores, denotando que

Os regentes vivam num universo fechado, onde não chegavam os jornais, a rádio, a luz (...). Não temos conhecimento que participassem em encontros com outros docentes, onde tivessem oportunidade de confrontar experiências, iniciativas, ou apenas tirar dúvidas" (RIAS, 1997, p. 121).

Com efeito, os textos de muitas dessas conferências eram publicados na EP na forma de artigos, todavia aquelas destacadas no quadro anterior, de cujos títulos se podem inferir uma abordagem mais específica acerca da escola rural, não foram publicadas na revista. De um lado a EP 
apenas refletiu o silenciamento da DGEP no tocante à escola rural (que elencou esse tema como objeto de poucas conferências), mas, de outro, o aprofundou ao não divulgar os textos referentes ao tema em questão, ou seja, o conteúdo não encontrou espaço em suas inúmeras páginas.

\section{Considerações Finais}

Os resultados da pesquisa possibilitam compreender que, no período 1934 a 1939, quando o Estado Novo propalava os seus "investimentos" na escola primária com vistas a combater os altos índices de analfabetismo ainda registrados em Portugal e no momento em que a população portuguesa vivia majoritariamente no campo, a EP não destinou nenhum espaço específico em seus editoriais para discutir os problemas subjacentes à escola primária rural ou sequer noticiou o seu funcionamento. Além de esse tema não ter sido objeto de apreciação em seus editoriais, foi pouco debatido nas demais seções publicadas. O rural, suas escolas, professores, alunos, problemas e práticas docentes permaneceram como um "não assunto" na revista "oficial" destinada a contribuir para a organização do ensino primário e a orientar os professores.

A exceção a esse silêncio, conforme discutimos, foi localizada nos artigos da inspetora Felismina Oliveira, denominados "Realidades" e nos inquéritos do médico José Lopes Dias, intitulados "Apontamentos de higiene das escolas primárias". No entanto, segundo apresentamos, tanto as crônicas quanto os inquéritos não tiveram continuidade.

Avaliamos que uma das causas para esse silêncio incidiu sobre o projeto de implementação de uma escola primária única e, por conseguinte, às iniciativas de homogeneizá-la. Nesse sentido, noticiar as instituições rurais de ensino implicaria destacar as suas idiossincrasias (a existência dos postos de escolares, a insuficiente qualificação e estatuto sócio-profissional diferenciado dos seus docentes) e, consequentemente, revelar o malogro da desejada unidade da escola primária.

$\mathrm{Da}$ análise do contexto em que a EP surgiu, concluímos que, a despeito das iniciativas efetivadas pelo governo ditatorial para criar uma escola primária única, tanto do ponto de vista legal, quanto de direito, existia uma escola primária rural diferenciada da escola primária urbana. 
A criação dos postos de ensino, posteriormente elevados à condição de postos escolares, e a regulamentação do pessoal docente para atuar nesses estabelecimentos na categoria de regentes de postos (de ensino) escolares, com nível de qualificação, assim como salários e outras garantias inferiores àquelas exigidas e garantidas aos professores primários, revelam a existência de condições distintas na oferta do ensino primário à população rural.

Se essa escola primária rural, que funcionava em condições diversas da urbana, era um fato social, a revista Escola Portuguesa, ao ignorá-la e não destinar espaço em seus editoriais para a discussão do seu funcionamento, esquivava-se de evidenciá-la e não a incorporava como um objeto de estudo. Em função desse resultado, acreditamos que a apologia à vida rural, que no dizer de Mónica (1978) constituiu-se no ponto-chave da ortodoxia Salazarista, ainda não se havia consolidado por meio da visibilidade da escola rural na EP durante o período de 1934 a 1939.

Além disso, conferir destaque ao modo de vida rural parece ter se constituído em uma operação alheia à divulgação da "escola" existente no meio rural, posto que as condições de funcionamento desses estabelecimentos não ofereciam elementos para a propaganda do Estado Novo, devido, por exemplo, às precárias instalações dos postos escolares que, no dizer de Adão (1984, p. 70), “[...] manifestam o desprezo dos governantes no que respeita não só à alfabetização, mas também à valorização cultural das populações rurais".

Perguntaríamos, então, se, subjacente ao silêncio sobre a escola rural nos editoriais desse período, não estaria presente um dado "tabu", tal qual analisa Carneiro (2003, p.7) no prefácio ao livro de Marc Ferro? Afinal, segundo essa historiadora: “'Tabu' tem a ver com algo perigoso de ser dito, interdito; algo que estorva, vedando o acesso a certos bens, espaços e informações". Com efeito, do editorial, tanto nos temas abordados, quanto nos autores privilegiados, passando pelos artigos até a legislação publicada, as páginas da revista eram espaços privilegiados para apresentar e louvar os feitos do governo. Decorre desse fato que, ao silêncio a respeito da escola rural subjazia a preocupação em não revelar claramente a fragilidade do Estado Novo no que concernia, principalmente, ao ensino primário. Concluímos, portanto, que, mais que um veículo de 
formação e informação aos professores primários, a EP se consolidou como um importante instrumento de propaganda para o Estado Novo em Portugal junto a esses professores.

\section{REFERÊNCIAS}

ADÃO, Áurea. O Estatuto Sócio-Profissional do Professor Primário em Portugal (1901-1951). Lisboa: Fundação Calouste Gulbenkian, 1984.

. A Escola em Meio rural no Portugal dos Primeiros Anos do Estado Novo. A Formação dos seus Professores no(s) Discurso(s) do poder Político. In: WERLE, F. O. C. (Org.). Educação rural em perspectiva internacional - instituições, práticas e formação do profesor. Ijuí: UNIJUÍ, 2007. p. 269-294.

AINDA sôbre as visitas ministeriais às escolas. Escola Portuguesa, Lisboa, n. 174, p. 271-272, Fev. 1938.

ALEIXO, M. I.; ALVES, M. do C. A Cultura Escolar e a Formação dos Mestres de Ensino Primário na Escola Rural, Através da Produção Escrita dos Alunos, de 1956 a 1960. In: WERLE, Flávia O. C. (Org.) Educação rural em perspectiva internacional - instituições, práticas e formação do profesor. Ijuí: UNIJUÍ, 2007. p. 335-369.

ALMODÓVAR, A. A Educação da juventude. Escola Portuguesa, Lisboa, n. 55, p. 33-34, Out. 1935.

AMIGUINHO, Abílio. Educação e Mundo Rural: percursos biográficos, intervenção e pesquisa. Educação, Sociedade \& Culturas. n. 20, CIIE/ Edições Afrontamento: Porto-Pt, p. 9-42, 2003.

BENSAÚDE, R. ¡Já se bateu com 3:000 quilómetros! Escola Portuguesa, Lisboa, n. 28, p. 525, Abr. 1935.

CANÁRIO, R. A Escola no Mundo Rural: contributos para a construção de um objeto de estudo. Educação, Sociedade \& Culturas. n. 14, CIIE/ Edições Afrontamento: Porto-Pt, p. 121-139, 2000.

CARNEIRO, Maria L. T. Prefácio. In: FERRO, M. Os tabus da história a face oculta dos acontecimentos que mudaram o mundo. Rio de Janeiro: Ediouro, 2003. p. 7-10. 
CARVALHO, R. de. História do Ensino em Portugal - Desde a fundáção da nacionalidade até o fim do regime de Salazar-Caetano. 5. ed. Lisboa: Fundação Calouste Gulbenkian, 2011.

CORREIA, L. G. Portugal pode ser, se nós quisermos, uma grande e próspera nação. O sistema educativo no Estado Novo. Ler História. Lisboa, n. 35, p. 71-107, 1998.

DIAS, J. L. Apontamentos de higiene nas escolas primárias... Escola Portuguesa, Lisboa, n. 156, p. 16-18, Out. 1937.

DISCURSO proferido por S. Ex ${ }^{\text {a }}$ o Ministro da Educação Nacional... Escola Portuguesa, Lisboa, n. 184, p. 390-394, Maio 1938.

DO ANO escolar que findou. Escola Portuguesa, Lisboa, n. 145, p. 292297, Ago. 1937.

DOCUMENTOS Gráficos. Escola Portuguesa, Lisboa, n. 55, n. p., Out. 1935.

EM TODA a parte seremos sempre educadores. Escola Portuguesa, Lisboa, n. 150, p. 322-323, Set. 1937.

É NECESSÁRIO renovar-se o estudo dos programas. Escola Portuguesa, Lisboa, n. 156, p. 14-15, Out. 1937.

ESCOLA PORTUGUESA. Lisboa: DGEP, 1934-1939.

A ESCOLA veste-se de novo. Escola Portuguesa, Lisboa, n. 69, n.p., Fev. 1936.

FESTA da Nação e festa da escola. Escola Portuguesa, Lisboa, n. 72, p. 133-137, Fev. 1936.

GRAÇA, L. Q. Embelezamento da ida rural. Escola Portuguesa, Lisboa, n. 53, p. 17-18, Out. 1935.

GUEDES, Lília A. X. A. Escola Portuguesa (1934-1957) - Sobre a política educativa do Estado Novo. 1998. 198f. Dissertação (Mestrado em Educação), Universidade do Minho, Braga, 1998.

GUERRA, J. R. Lopes A. João Baptista Vilares - um educador e um mensageiro do progresso no meio rural. 2006. 152f. Dissertação (Mestrado em Ciências da Educação) - Faculdade de Psicologia e Ciências da Educação, Universidade de Lisboa, Lisboa, 2006. 
LEAL, A. Os serviços do ensino primário [...]. Escola Portuguesa, Lisboa, n. 41, Jul. 1935.

LER, escrever e contar não constituem uma ciência. Escola Portuguesa, Lisboa, n. 4, p. 51-52, Nov. 1934.

LIMA, S. C. F. de. Historia das escolas rurais em Uberlândia (1933 a 1959). In: PÉREZ, T. G.; PÉREZ, O. L. (Org.). Educación rural en Iberoamerica. Experiencia histórica y construcción de sentido. v. 1. Madrid: Anroart Ediciones, 2009. p. 153-182.

MARTINS, E. C. A Memória Histórica dos Edifícios Escolares no Portugal Rural a arquitectura escolar das escolas primárias na Beira Interior. In: WERLE, F. O.C. (Org.). Educação rural em perspectiva internacional instituições, práticas e formação do profesor. Ijuí: UNIJUÍ, 2007. p. 295334.

MELO, J. M. de. Jornalismo opinativo: gêneros opinativos no jornalismo brasileiro. 3. ed. rev. e ampl. Campos do Jordão: Matiqueira, 2013.

MÓNICA, M. F. Educação e sociedade no Portugal de Salazar. Lisboa: Editorial Presença, 1978.

NOTÍCIA do presidente do júri de Bragança, Bernardino Guedes de Miranda, director dêsse districto escolar. Escola Portuguesa, Lisboa, n. 105, p. 26-27, Out. 1936.

OBRA das Mães pela Educação Nacional... Escola Portuguesa, Lisboa, n. 94, p. 297-298, Jul. 1936.

OLIVEIRA, F. Enquanto espero o eléctrico. Escola Portuguesa, Lisboa, n. 71, p. 127-128, Fev. 1936.

1939a.

. Realidade... Escola Portuguesa, Lisboa, n. 237, p. 379-380, Maio

_. Realidades... Escola Portuguesa, Lisboa, n. 246, p. 446-447, Jul. 1939b. $1939 \mathrm{c}$.

Realidades... Escola Portuguesa, Lisboa, n. 246, p. 459-459, Jun.

PORTUGAL. Decreto-Lei n. 22.369, de 30 de março de 1933. Diário do Governo, Lisboa, 30 de março de 1933, n. 73, 1 Série. p. 414-436. 
Disponível em: < http://dre.pt/pdfgratis/1933/03/07300.pdf> . Acesso em: 08 Mar. 2013.

PORTUGAL. Decreto n. 20.604, de 09 de dezembro de 1931. Diário do Governo, Lisboa, 09 de dezembro de 1931, n. 283, 1 Série. p. 2680-2681. Disponível em: <http://dre.pt/pdfgratis/1931/12/28300.pdf>. Acesso em: 12 Fev. 2013.

PORTUGAL. Decreto n. 27.279, de 24 de novembro de 1936. Diário do Governo, Lisboa, 24 de novembro de 1936, n. 276, 1 Série. p. 1510-1511. Disponível em: <http://dre.pt/pdfgratis/1936/11/27600.pdf>. Acesso em: 03 Mar. 2012.

PORTUGAL, M. A Estatística. Escola Portuguesa, Lisboa, n. 92, p. 319, Ago. 1936.

RAMALHO, A. Benéficos ou funestos podem ser os educadores. Escola Portuguesa, Lisboa, n. 10, p. 165-166, Dez. 1934.

RAMOS, R. O chamado problema do analfabetismo: as políticas de escolarização e a persistência do analfabetismo em Portugal (séculos XIX e XX). Ler História, Lisboa, n. 38, p. 45-70, 1998.

RECOMEÇANDO. Escola Portuguesa, Lisboa, n. 154, p. 1-3, Out. 1937. REFLEXÕES sôbre a finalidade escolar. Escola Portuguesa, Lisboa, n. 155, p. 9-10, Out. 1937.

REFORMA do ensino primário. Escola Portuguesa, Lisboa, n. 162, p. 89113, Dez. 1937.

RIAS, A. P. L. A. Regentes Escolares: colaboradores benévolos ao serviço da Educação Nacional. 1997, 2v. Dissertação (Mestrado em História Contemporânea) - Faculdade de Filosofia, Universidade Nova de Lisboa, Lisboa, 1997. [texto policopiado].

SANTOS, Gomes. Na defesa da língua. Escola Portuguesa, Lisboa, n. 60, p. 69-70, Dez. 1935.

SERVIÇOS de administração e disciplinares. Escola Portuguesa, Lisboa, n. 51, p. 920-922, Dez. 1935a.

. de orientação pedagógica e aperfeiçoamento do ensino primário.

Escola Portuguesa, Lisboa, n. 16, p. 295-296, Jan. 1935 b. 
SIMÕES, M. E. B. R. Representações sociais da escola rural em meados do século XX em Portugal. 1999. 181f. Dissertação (Mestrado em Psicologia Educacional) - Faculdade de Ciências Sociais e Humanas. Universidade Nova de Lisboa. Lisboa, 1999.

VALENTE, J. C. As Casas do Povo e a educação popular no Estado Novo (1933-1970). Revista História, Lisboa, n. 21, p. 40-49, Jun. 1996.

VIANA, A. G. M. Relatório do presidente do júri que funcionou em Faro. Escola Portuguesa, Lisboa, n. 52, p. 12, Out. 1935.

A VISITA de S. Ex ${ }^{\mathrm{a}}$. o Ministro da Educação Nacional às escolas e postos escolares do Algarve. Escola Portuguesa, Lisboa, n. 140, p. 251-252, Jul. 1937.

Data de registro:13/05/2013

Data de aceite: 08/07/2013 